\title{
Investigating Arabic to Speakers of Other Languages (ASOL) Lecturers' Attitudes towards Utilizing Flipped Classroom Instruction (FCI): A Qualitative Study at Jordanian Public Universities
}

\author{
Ibraheem Hasan Al rababah ${ }^{1} \&$ Luqman Rababah $^{2}$ \\ ${ }^{1}$ Languages Centre, University of Jordan, Amman, Jordan \\ ${ }^{2}$ School of Arts and Languages, Jadara University, Irbid, Jordan \\ Correspondence: Luqman Rababah, School of Arts and Languages, Jadara University, Irbid, Jordan. P. O. BOX \\ 733, Postal Code 20110, Jordan. Tel: 962-7201-2222. E-mail: Rababah80@gmail.com
}

Received: December 3, 2016

doi:10.5539/ies.v10n7p94

\author{
Accepted: January 6, 2017 \\ Online Published: June 27, 2017 \\ URL: https://doi.org/10.5539/ies.v10n7p94
}

\begin{abstract}
Although Flipped Classroom Instruction (FCI) is not a new concept, the practice is relatively new in the Arab region, especially, in Jordan, where the face-to face approach is still widely used. This qualitative study examined the attitudes of Arabic language lecturers at three Jordanian public universities towards utilizing FCI in their instruction. With the help of convenience sampling, eight lecturers were selected to participate in the study. To reach a clear understanding of this issue, the study utilized a qualitative design and semi-structured interviews were used as a tool to collect the data. The findings revealed that the attitudes of ASOL lecturers about using FCI in their instruction were generally positive. Through the analysis of the data, three main themes emerged from the interviews. The themes were: 1) increasing interaction and collaborative learning, 2) encouraging learning autonomy and independence, and 3) peer instruction and feedback. A key recommendation of the study is that further research needs to be conducted into the reasons why some teachers had negative attitudes towards FCI.
\end{abstract}

Keywords: flipped classroom, blended learning, ASOL, attitudes, lecturers

\section{Introduction}

Educators and researchers have stressed the important role that student-centred approaches play in developing students learning (Ke \& Kwak, 2013; Li \& Guo, 2015), and this approach has reformed teaching styles in many aspects of our daily lives. With the help of this approach, learners are exposed to more flexible, student-centred classroom teaching methods, which are based on the concepts of "discovery" learning and "active" learning environments (Greitzer, 2002). Although teacher-centred classroom instruction is widely common, this method has been recently criticized for its failure in providing active learning for learners (Muldrow, 2013). In such an environment, students are passive learners, whereby they rely on learning by listening, memorizing, and the repetition of the taught knowledge (Danker, 2015). In the student-centred approach, on the other hand, students are eager to learn more by means of the structuring of their learning and by making sense of that learning. Thus, students become active, and the teacher becomes more of a mentor and facilitator of knowledge rather than the dominant content expert.

Thus, the need for an innovative pedagogical approach that focuses on engaging students in active learning has been raised (Li \& Guo, 2015). Education should be focused on learning to learn, developing skills and strategies for continuous learning, and building meaningful experiences of learning that are pertinent to the life of the learner and learner development (Williams, Watts, MacLeod, \& Mathews, 1997). Accordingly, Jordan has decided to make a big shift from a teacher-centred approach to a student-centred approach (Ministry of Education, 2010). The Jordanian educational system encourages excellence, stresses the needs of learners, and allows universal access to educational opportunities, facilitates equality in the provision of services, promotes the use of modern Information and Communication Technology (ICT) tools, and offers the best teaching and learning strategies and methods to promote student success (Rababah \& Melhem, 2015). A promising possibility that could help in the shift is the Blended Learning (BL) approach (Al-Shboul, Rababah, Al-Saideh, Betawi, \& Jabbar, 2013; Almarabeh, Hiba, Rana, \& Majdalawi, 2014; Bawaneh, 2011; Obeidat \& Abu-Shanab, 2010), which implies a paradigm shift in the teaching methodology. This shift is assumed to lead to more productive 
learning outcomes and to allow class time to be utilized for practical learning instead of focusing on the old-fashioned approach. Flipped Classroom Instruction (FCI), which can be categorized as one of the BL models, has become very popular as a way of introducing technology in teaching in higher education (Al-Qahtani \& Higgins, 2013; Strayer, 2012; Tai \& Ting, 2011). In fact, teaching and learning of a language requires capabilities in the field of ICT and probably carries with it a major shift in classroom practices. Teaching and learning a language skills with the help of ICT has become a significant necessity for educational expansion and overall development worldwide (Abuhmaid, 2011; Al-Qahtani \& Higgins, 2013).Therefore, the integration of ICT into education is a step in the correct direction as we move forward in the $21^{\text {st }}$ century because ICT could be used as an approach that focuses on student-centred education (Danker, 2015). In the context of Jordanian universities, ICT is offered to help students and teachers to introduce learning materials and make those materials simpler and more effective (Al-Shboul et al., 2013).

\subsection{Statement of the Problem}

Despite the best efforts expended by the Hashemite Kingdom of Jordan in launching modern educational reforms, several studies have revealed that university lecturers still have had problems with using new approaches in their instruction (Al-Adwan, Al-Adwan, \& Smedley, 2013; Al-Shboul et al., 2013; Bawaneh, 2011; Obeidat \& Abu-Shanab, 2010). However, research on FCI in an Arab context is scarce compared with that done in Western countries (Ahmed, 2016; Al-Zahrani, 2015; Alharbi, 2015; Farah, 2014). Even those previous studies conducted in the Arab context were not in an Arabic language context. Thus, researchers in the region including (Ahmed, 2016; Al-Zahrani, 2015; Alharbi, 2015; Farah, 2014) and in Jordan including (Al-Adwan et al., 2013; Bawaneh, 2011; L. Rababah, Melhem, Jdaitawi, B. Rababah, \& O. Rababah, 2012; Obeidat \& Abu-Shanab, 2010) have requested that additional studies should address the issue. One key factor behind researching this topic and conducting interviews at the universities selected for study is to bring attention to FCI and to identify the attitudes of ASOL lecturers towards the utilization of FCI in their instruction. Arabic language learners face difficulties including the teaching and learning approaches adopted by teachers inside the classroom (Al-Gomoul, 2011) because Arabic is one of the most difficult languages to learn (Seraj, 2010). Thus, teachers must adopt modern methods to teach the Arabic language effectively (Jassem, 2000). Moreover, teachers must enhance their teaching methods by blending ICT into their instruction to capture a learner's attention (Ashton \& Zalzala, 2000). This justifies the purpose of the current study which is to investigate attitudes of ASOL lecturers in Jordan and to answer the following research question: What are the attitudes of ASOL lecturers towards utilizing FCI in instruction?

\subsection{Significance of the Study}

The current study contributes to the literature concerning FCI in the context of Jordan and in the Arab region. This study has adopted a fully qualitative research design to get an in-depth, clear picture in a natural setting. More importantly, the present study is unique because it focuses on the attitudes of ASOL lecturers toward utilizing FCI in their instruction. Identifying the attitudes of the lecturers toward these methods could be of great help in defining the starting point for training programs. Moreover, understanding lecturers' attitudes about FCI could help educators articulate their objectives more clearly both in curriculum requirements and in professional preparation and training. Finally, this study will fill gaps in the literature and answer the calls of prior researchers (Ahmed, 2016; Al-Zahrani, 2015; Alharbi, 2015; Farah, 2014) to carry out such a study on FCI in the region and specifically in Jordan (Al-Shboul et al., 2013; Almarabeh et al., 2014; Bawaneh, 2011; Rababah et al., 2012).

\section{Literature Review}

\subsection{Theory of Reasoned Action (TRA)}

The Theory of Reasoned Action (TRA) has been considered one of the most influential theories of human behaviour (Ajzen \& Fishbein, 2005). According to Ajzen and Fishbein (2005), who have developed the TRA, human behaviour is influenced by the intention to execute a behaviour. This intention forms under the impact of attitudes toward the behaviour and the subjective norm and the beliefs of relevant others in relationship to the behaviour. This is determined by two components: one being normative beliefs stemming from the relevant social group and the other being the motivation to comply with the referent others (Ajzen \& Fishbein, 2005). In other words, a positive attitude toward behaviour together with a positive subjective norm forms an individual's intention to engage in the behaviour, and, in turn, results in performance.

An attitude toward a certain act is posited to be a function of the act's perceived consequences and of value of that act to the person (Ajzen \& Fishbein, 2005). Strong attitudes are a good predictor of behaviour, as they are relatively stable over time, and unaffected by persuasion, especially when they are supported by chronically accessible beliefs (Ajzen, 2005). Attitudes play a significant role in shaping our world view and determine how 
we react to different things present in the world (Oppenheim, 1998). Attitudes influence our perception of the world around us and determine how we react to different things of the world. According to Oqaily (2013), attitudes help in gaining insights into the language learning and teaching process. To conclude, positive attitudes toward learning targeting language lead to a higher level of motivation.

\subsection{History of FCI}

The integration of ICT into both learning and teaching is a concept that is as old as technology, but the increasing development of emerging technology like web-based technology has made technology become more popular among educators. Educators are of the consensus that ICT has the potential to enhance the learning outcomes of students and the effectiveness of those outcomes when properly utilized (Wang and Woo, 2007). In this context, integration has a sense of completeness about it (Earle, 2002) upon which all significant elemental systems are combined to form a whole. ICT integration refers conceptually to the use of technology as a powerful tool to assist students in learning different content areas and analysing and solving problems with the help of newly learned skills and knowledge in order to tackle real-life situations. ICT integration has been linked to the promotion of student learning via collaborative involvement in actual, challenging tasks that stem from different disciplines in the context of complex environments for the inquiry and activity of students. The constructivism approach to ICT integration has been deemed as providing distinct opportunities for a transformative method of teacher education.

Today, educators have come to realize the importance of the use of an integrated combination of traditional learning with web-based online approaches, which is known as Blended Learning (Strayer, 2012). Blended Learning (BL) can increase access and flexibility for learners, increase the level of active learning, and achieve better student experiences and outcomes (Bonk \& Graham, 2006). BL involves utilizing a combination of online interactions and face-to-face interactions in the same course (Oliver \& Trigwell, 2005). The goal of BL is to facilitate greater student learning and could thus fit within the context of learner-centredness, which is one distinct feature of the characteristics of the Communicative Language Approach (CLA). Considering the increased acknowledgement of the benefits of interactive and collaborative learning, constructivism has been seen to impact CLA by its stress on learner-centred teaching methods and the significance of language use in communication and making meanings (Hymes, 1971). Several distinct characteristics of the CLA approach can be derived from the literature, which are: 1) authentic materials, 2) pair and group work and 3) creative and critical thinking (Richards \& Rodgers, 2001).

In a knowledge-based, technology-driven society, learners are no longer considered the passive recipients of information. Instead, they are more potentially enabled to progress and are more actively engaged, motivated, autonomous and independent. Learner autonomy is a term widely used to describe independent, life-long learning, which is an essential skill in the current, modern lifestyle (Farah, 2015). It has also been acknowledged that learning can occur in several ways, specifically with engaged and active learners (Gerjets, Scheiter, Opfermann, Hesse, \& Eysink, 2009). Learning is considered to be more effective and productive if that learning is focused on a goal and regulated by the learner, and if that learning occurs in interactions and collaboration with others. Learning is also effective if is based on constructive knowledge processes and the acquisition of skills (Buchberger, 2001). In this regard, Vygotsky indicates that the only effective learning is that which is in advance of development, meaning that learning results in mental development and that the Zone of Proximal Development (ZPD) facilitates different processes of development.

Vygotsky's emphasis is on the manner in which language impacts learning and in which learning is improved through social interaction. Vygotsky's (1978) notion of the ZPD posits that the learner is brought towards a higher degree of performance via his/her peer's and his/her instructor's support. Vygotsky provided a conceptualization of the learning-development relationship in his ZPD in which he posits that development is a continuum of behavioural development (Vygotsky, 1978). The teacher facilitates the learner's independent acquisition by direct assistance and, as the learner progresses in his/her achievement of the independent level, the ZPD also attains a higher degree. When a teacher incorporates collaborative learning in the classroom, that teacher becomes more of a mentor and facilitator of knowledge instead of the dominant content expert. Flipped Instruction can be categorized as one of the BL models. According to Strayer (2012), an inverted (or flipped) classroom is a specific type of blended learning design that uses technology to move lectures outside the classroom and uses learning activities to move practice with concepts inside the classroom. FCI started specifically in the classrooms of two high school chemistry teachers, Jonathan Bergmann and Aaron Sams (Bergmann \& Sams, 2012). They used live video recordings and screen casting software to record lectures, demonstrations, and slide presentations with annotations and posted them for the students to watch and read (Hamdan, McKnight, McKnight, \& Arfstrom, 2013). 
Recently, the adoption of the flipped classroom approach has begun to extend from primary and secondary education to the undergraduate level. Today, universities and colleges remain attentive to developing and supporting ways to foster student academic success. In the Flipped Instruction Rotation Model, learners are more focused on and responsible for their learning. They have greater opportunities to draw connections between the learning that they have done at their own pace before coming to class. Thus, classroom activities reinforce their learning. Bergmann, Overmyer and Willie (2011) listed several of advantages of utilizing the flipped (inverted) classroom. These include:

- Increased engagement in the learning material: Students are encouraged to complete active learning exercises that illustrate the applications, implications and/or controversies associated with the material. During class, students ask questions and receive personalized and instant feedback.

- Development of life-long learners: Learning the assigned material before attending the class with the use of ICT could help students improve and apply different learning strategies (computer skills and knowledge acquisition).

- Enhanced interaction between student and faculty: Using flipped learning moves the faculty members from the stage to interaction between faculty and students.

\subsection{Empirical Studies}

Several empirical studies help to clarify the understanding of previous related research and also to understand from whence this current study started and to show the gaps in the existing studies (Adedoja, 2016; Alfahadi, Alsalhi, \& Alshammari, 2015; Cakir, 2015; Lazareva, 2015; Uzunboylu \& Ozdamli, 2011).To start with, Adedoja (2016) examined the attitude of pre-service teachers towards flipped learning, and the challenges these teachers faced. The study employed the descriptive research method; questionnaires and focus-group discussion were used to gather data. A total of 273 pre-service teachers participated in the study. The results showed that the pre-service teachers had positive attitudes towards flipped learning. Similarly, Lazareva (2015) explored teachers' opinions of flipped classrooms with respect to the quality of learning, student-teacher relationships, and student engagement. The data collection process comprised in-depth, face-to-face interviews with teachers. The collected data were analysed using the thematic method. The majority of participants found the flipped classroom teaching method to be beneficial for improving students' motivation and engagement, promoting effective learning, and efficiently allocating teaching time.

Moreover, Cakir's (2015) study aimed at exploring the use of mobile phones in a foreign language teaching context by prospective teachers. The study utilized a quantitative methodology. In this context, a questionnaire was developed and administered to a sample of 193 participants. The data gathered through the questionnaire were processed and analyzed descriptively. Results indicate that most of the participants would prefer to use mobile phones as instructional tools in foreign language learning. The results also provided some insights as to how foreign language teachers could employ suitable approaches to make learning and teaching English meaningful and communicative. The results suggested that the participants would like to make use of mobile phones for educational purposes when they become teachers of English.

Additionally, Alfahadi et al (2015) investigated EFL teachers' views on blended learning. The study sample included 35 EFL Saudi teachers in Tabuk City, KSA. In order to collect the data required, the researchers developed a questionnaire that consisted of two sections, namely, process and content. The results indicate that the teachers' views toward blended learning were generally positive. Moreover, it was interesting to see that EFL teachers were highly optimistic about how blended learning would help them in improving their performance and how it would motivate their students to learn English. Uzunboylu and Ozdamli (2011) carried out research to illustrate attitudes towards technology-based cooperative learning. They found that the participants developed significantly positive attitudes towards technology at the end of the experiment.

However, research on FCI in an Arab context is scarce compared with that done in Western countries (Ahmed, 2016; Al-Zahrani, 2015; Alharbi, 2015; Farah, 2014). Even those previous studies conducted in the Arab context were not in an Arabic language context. Thus, researchers in the region including (Ahmed, 2016; Al-Zahrani, 2015; Alharbi, 2015; Farah, 2014) and in Jordan including (Al-Adwan et al., 2013; Bawaneh, 2011; Obeidat \& Abu-Shanab, 2010) have requested that additional studies should address the issue. Moreover, researchers have attributed university lecturers' problems to the low utilizing of new approaches in their instruction (Al-Adwan et al., 2013; Al-Shboul et al., 2013; Bawaneh, 2011; Obeidat \& Abu-Shanab, 2010)

\section{Method}

The present study used a qualitative approach to obtain data from lecturers of three Jordanian universities, 
Yarmouk University, Al Al-bait University, and University of Jordan, to determine the answers to the research question during the academic year 2015-2016. Denscombe (2010) and Creswell (2013) stated that such an approach is advantageous for the following reasons: first, there is richness and detail to the data; second, the data and the analysis are usually grounded and; third, there is the prospect of alternative explanations. Thus, these reasons justify using such an approach in this study. The selected universities have had a long history characterized by reform projects and initiatives. Currently, they provide smart boards, data showing projectors, wireless access points for classrooms, conduct upgrades of computer laps and lab technicians.

\subsection{Data Collection Instrument}

This study employed semi-structured interviews. During actual study, every lecturer was requested to respond to five questions revolving around their attitudes towards the implementation of FCI in instruction. Semi-structured interviews have several advantages, including enhancing the accuracy of the individual's responses, enabling the informant's free responses, and enabling the researcher to follow up upon ideas, to investigate, develop and clarify answers while the interview is going on. In addition, semi-structured interviews also enable the researcher to develop his or her own interview guide without having to strictly follow question lists word for word (Creswell, 2013; Denscombe, 2010).

\subsection{Trustworthiness and Credibility}

To confirm the content and face validity of the instrument, the researchers conducted trial interviews with the participants. In this study, trial interviews were carried out as the researchers practised the interview strategies. These trial interviews benefited both the researchers and the actual future participants as the trails were carried out to ensure their effectiveness in the actual study. The benefits were several. First, the content and face validity of the instruments were confirmed through improving questions, wording sequences and format. Second, the researchers were able to enhance their skills in interviewing. Third, the researchers were able to enhance their interview methods through the correct estimation of the duration of the process in an actual setting (Creswell, 2013; Denscombe, 2010).To check the trustworthiness and credibility of qualitative data, the researcher also utilized the member check strategy. According to Denscombe (2010), member check is an invaluable method for establishing the credibility of findings. Member checking is a method in which the researcher requests the help of one or more participants in the study to recheck the accuracy of their accounts. This is a process whereby the researcher presents the findings to the participants and lets them go through them to verify their accuracy and to go through various aspects of the study verifying their completeness, realism, accuracy and fairness of representation (Creswell, 2013; Denscombe, 2010).

\subsection{Population and Sampling of the Study}

By means of a convenience sample selected from the population, the researcher collected data from three Jordanian universities, namely, Yarmouk University, Al-Albait University, and University of Jordan. The researcher selected participants because they were willing and available to be studied (Creswell, 2013). Table 1 shows that the participants for this study comprised ASOL lecturers who teach different levels of students. The selected teachers were males and females who were selected after going to the three selected universities.

Table 1. Participants for the study

\begin{tabular}{|c|c|c|c|c|c|}
\hline Lecturer & Level of Education & Computer Literacy & Gender & Years of Experience & Age \\
\hline LA & Master's degree & ICDL & Female & $5-9$ & $30-34$ \\
\hline LB & $\mathrm{PhD}$ & ICDL & Female & $15-19$ & $35-39$ \\
\hline LC & Master's degree & INTEL & Female & $10-14$ & $40-44$ \\
\hline LD & $\mathrm{PhD}$ & ICDL & Female & $10-14$ & $35-39$ \\
\hline LE & $\mathrm{PhD}$ & ICDL & Male & $10-14$ & $40-44$ \\
\hline LF & $\mathrm{PhD}$ & Other & Male & $5-9$ & $35-39$ \\
\hline LG & Master's degree & Other & Male & $5-9$ & $30-34$ \\
\hline LH & $\mathrm{PhD}$ & Other & Male & $5-9$ & $30-34$ \\
\hline
\end{tabular}

Note. ICDL $=$ International Computer Driving Licence; INTEL $=$ Intel Teach to the Future; and Other $=$ Word Links and Network Management courses.

A total of eight lecturers were involved in this study. For reasons of confidentiality in this research, the lecturers are identified only through codes. 


\subsection{Data Analysis}

To analyse the data, this study followed Creswell's recommended steps using the bottom-up approach. Creswell (2013) recommended six steps that a researcher should use as guidelines for collecting, analysing and interpreting qualitative data. These included: 1) organizing and preparing the data for analysis, 2) reading through all the data, 3) developing and using a coding process, 4) using the coding process to generate a description of the setting or people as well as categories of themes for analysis, 5) advancing how the categories and themes will be represented in the qualitative narrative, and 6) making an interpretation or meaning of the data. With this sizable amount of data, the researcher developed a matrix or a table of sources to help organize the material.

\section{Results and Discussion}

The present study examined the attitudes among the participants of the selected Jordanian universities in Jordan. In order to achieve the aim of the study, interviews were utilized on a convenience sample comprising eight participants. The present chapter presents the results and discussion based on the tool used to answer the following research question:

Question One: What are the attitudes of ASOL lecturers towards utilizing FCI in instruction?

Through the analysis of data, three main themes were emerged from the interviews. The themes were: 1) increasing interaction and collaborative learning, 2) encouraging learning autonomy and 2) independence, and peer instruction and feedback.

\section{First theme: Increasing interaction and collaborative learning}

Most of the participating lecturers (LA, LB, LC, LE, LF and LH) expressed their opinions on how FCI helps in improving interaction and collaborative learning strategy among students. For example, participant LH claimed that "...during FCI, the focus is on collaborative learning in which students displaying different levels of performance worked together in small groups to interact and achieve a common goal" (LH, Interview, July 3, 2016). Similarly, LE mirrored the above statement by saying, "the students are accountable and responsible for their learning and for others. Hence, the success of one student could help in the success of others" (LE, Interview, July 2, 2016). LG and LD were against the utilizing FCI. LD stated that "some students are not as motivated as others, and FCI may allow those less motivated students to get less done... It would become rather tricky to make sure everyone is learning at a steady pace" (LD, Interview, July 7, 2016).

Obviously, FCI encourages and promotes the maximum use of cooperative activities based on pair work and group work of learners in the classroom (Johnson, Johnson, \& Smith 1991). A theory of language as communication lies at the core of Collaborative Learning Theory. Hymes (1971) advanced the notions of "competence" and "performance" that Chomsky (1968) introduced in the 1960s and stated that the goal of language teaching was to develop "communicative competence", which implies acquiring both the ability and the knowledge to use language. Therefore, the communicative approach promoted the idea that social and cultural knowledge were necessary prerequisites for understanding and using linguistic forms. Vygotsky's socio-cultural theory posited that human learning couldn't be understood independently from the social and cultural forces that influence individuals and that those sociocultural interactions are critical to learning.

\section{Second Theme: Encouraging learning autonomy and independence}

Most of the interviewed lecturers believed that FCI was important to encourage students' learning autonomy and independence. Six interviewees (LA, LB, LC, LE, LF and LH) gave positive feedback about the use of FCI in their instruction. According to LA, FCI "is a good strategy to apply in language learning settings as it consists of interactive group learning activities inside the classroom and direct computer-based individual instruction outside the classroom...." (LA, Interview, July6, 2016). Similarly, LF stressed the importance of FCI in by saying that "FCI is a very good and effective strategy as it saves time and lets the students have more practice and activities under the guidance of the teacher and encourages them to gain independence" (LF, Interview, July 9, 2016). LC stated that "FCI is more interactive than the old methods" (LC, Interview, July 13, 2016).

On the other hand, two lecturers (LD and LG) were unfamiliar with the FCI. One of them, LG, stated, "I have heard about FCI before but honestly I don't know how to implement such kind of strategies into instruction... I always implement the strategies I am familiar with" (LG, Interview, July 10, 2016). The participating lecturers employed FCI strategy in the class, which is based on Vygotsky's socio-cultural theory. Vygotsky (1978) posited that human learning cannot be understood independently from the social and cultural forces that influence individuals and those socio-cultural interactions are critical to learning. Conceptual and cultural learning occurs through dialogue in what Vygotsky called a ZPD. Importantly, when inducting students in to the teaching and 
learning process, a teacher must create a supportive but challenging environment, set the overall goals and direction, and clearly explain the rationale for such FCI, demonstrating, by appropriate micro-tasks, some of the procedures used for collaborative work. The current study revealed that many of the lecturers followed several principles of the FCI model to help students' learning autonomy and independence. For example, LF stated that he provided students with his support when needed, and teacher LA claimed that she provided her students with supervision and tried to enhance their independence.

\section{Third theme: Peer instruction and feedback}

Five participating teachers (LA, LB, LC, LE and LF) expressed their viewpoints concerning the use of FCI as a strategy to provide the students with peer instruction and feedback. The teachers highlighted the importance of peer instruction and feedback in teaching and learning process. Peers may be consulted for feedback based on the situation. The teachers' viewpoints on the strategy are provided below. LB stated "Teachers should familiarize themselves and train their students on how to use feedback in an effective manner to achieve both proficiency and competence as English writers" (LB, Interview, July1, 2016). Another lecturer (LF) stated that

During FCI, peer instruction is crucial step a teacher should train his/her students on. Students appear more confident and motivated as they are given the responsibility to edit and administer their peer's work. It could also encourage and facilitate resource and thoughts exchange and allow students to assess and evaluate their peer's work. (LF, Interview, July 9, 2016).

Similarly, LE stated that "during a traditional lecture, only a few highly motivated students get involved. While in FCI almost every student does participate in the process" (LE, Interview, July 2, 2016).On the contrary, three lecturers complained of being unable to use the FCI model (LH, LD and LG). LD stated that he did not use any type of feedback owing to constraints in time. He claimed that "There is not enough time to use FCI and peer instruction" (LD, Interview, July 7, 2016).

In this regard, Vygotsky talked about the benefits of peer instruction and feedback. He proposed the idea that learning and development take place in the interactions learners have with peers as well as with teachers and other adults. These social interactions develop language, and they provide feedback and assistance that support ongoing learning. One aspect of Vygotsky's Zone of Proximal Development in language acquisition is the role of feedback. In a FCI learning environment, students are free to ask questions, provide feedback and support their peers in learning the assigned material. Moreover, the teacher becomes more of a mentor and facilitator of knowledge rather than the dominant content expert. Feedback has the potential to be one of the most effective strategies used in classes because teachers can determine the level of the students' understanding and provide them with feedback in a timely manner. Peers may be consulted for feedback based on the situation. Peer Instruction engages students during class through activities that require each student to apply the core concepts being presented, and then to explain those concepts to their fellow students. A general consensus seems to exist among researchers that FCI plays a role in learning a language. Nassaji and Swain (2000) found that negotiated help provided within the learners' ZPD was more effective than help provided randomly. Nassaji and Swain (2000) supposed that, within Vygotsky's socio-cultural perspective and drawing upon Vygotsky's notion of the $\mathrm{ZPD}$, feedback can result in better and deeper learning.

\section{Conclusion}

The aim of this qualitative study was to examine the attitudes of ASOL lecturers at the selected universities utilizing FCI in their instruction. To answer the research question "What are the attitudes of Arabic language lecturers towards utilizing FCI in instruction?", this study utilized semi-structure interviews. The data were analysed using Creswell's six steps that a researcher should use as guidelines for collecting, analysing and interpreting qualitative data. This study examined the attitudes as they are the first determinant of individual intention to act. Based on TRA, attitude towards behaviour is the estimation of positive or negative self-evaluation in relationship to certain behaviour (Ajzen, 2005). The findings revealed that the majority of the interviewees believed that FCI is important to increase interaction and collaborative learning among students, encourage students' learning autonomy and independence and provide the students with peer instruction and feedback. Teachers who make use of ICT as a tool of teaching should feel confident enough to handle the method and should possess positive attitudes towards it.The study contributed by filling in the gaps in previous literature concerning FCI in an Arabic language environment in the context of Jordan and Arab region. This study answered the call that researchers have made, including Ahmed (2016), Al-Shboul et al. (2013), Bawaneh, (2011) and Farah (2014) who said that additional studies addressing FCI should be made. Understanding teachers' attitudes with respect to FCI could help educators articulate their objectives more clearly both in curriculum requirements, in professional preparation, and in training. These could provide program directors 
with the information necessary to support teachers in improving FCI strategies in their EFL instructions and to engage their students in helpful activities. In the FCI model, teachers are required not only to present lectures on videos and open class time for working on homework, but also to engage students in active, inquiry-based, and cooperative learning environments.

This study also has implications for policy makers and educators in terms of evaluating educational programs, materials and teaching strategies. The implication for teaching is that the flipped learning model is becoming increasingly popular in higher education, and universities and colleges. This research showed that the majority of interviewed lecturers are eager to use FCI in their instruction. This study recommends an experimental study to determine the effect of using FCI on students' progress. Future studies should also look into the reasons why some teachers had some negative attitudes towards using such an approach in their teaching practices. By answering the research question, this study has provided evidence supporting the implementation of FCI that could help develop Arabic language learners and also help bridge a critical gap in the literature of this field.

\section{References}

Abuhmaid, A. (2011). ICT training courses for teacher professional development in jordan. Turkish Online Journal of Educational Technology, 10(4), 195-210.

Adedoja, G. (2016). Pre-service teachers' challenges and attitude toward the flipped classroom. African Educational Research Journal, 4(1), 13-18.

Ahmed, M. A. E. A. S. (2016). The Effect of a Flipping Classroom on Writing Skill in English as a Foreign Language and Students' Attitude Towards Flipping. US-China Foreign Language, 14(2), 98-114.

Ajzen, I. (2005). Attitudes, personality, and behavior. McGraw-Hill Education:UK.

Ajzen, I., \& Fishbein, M. (2005). The influence of attitudes on behavior. In M. P. Z. D. Albarracín, \& B. T. Johnson (Eds.), The handbook of attitudes (pp. 173-221). Mahwah, NJ: Erlbaum.

Al-Adwan, A., Al-Adwan, A., \& Smedley, J. (2013). Exploring students acceptance of e-learning using Technology Acceptance Model in Jordanian universities. International Journal of Education and Development Using Information and Communication Technology, 9(2), 4-18.

Alfahadi, A. M., Alsalhi, A. A., \& Alshammari, A. S. (2015). EFL Secondary School Teachers' Views on Blended Learning in Tabuk City. English Language Teaching, 8(9), 51-85. https://doi.org/https://doi.org/10.5539/elt.v8n9p51

Alharbi, A. H. (2015). A Flipped Learning Approach Using Social Media in Health Informatics Education. Creative Education, 6(13), 144-166. https://doi.org/10.4236/ce.2015.613147

Almarabeh, T., Hiba, M., Rana, Y., \& Majdalawi, Y. K. (2014). The University of Jordan E-Learning Platform: State, Students' Acceptance and Challenges. Journal of Software Engineering and Applications, 7, 99-1007. https://doi.org/10.4236/jsea.2014.712087

Al-Qahtani, A. A. Y., \& Higgins, S. E. (2013). Effects of traditional, blended and e-learning on students' achievement in higher education. Journal of Computer Assisted Learning, 29(3), $220-234$. https://doi.org/10.1111/j.1365-2729.2012.00490.x

Al-Shboul, M., Rababah, O., Al-Saideh, M., Betawi, I., \& Jabbar, S. (2013). A vision to improve e-Learning at the University of Jordan. World Applied Sciences Journal, 21(6), 902-914. https://doi.org/10.5829/idosi.wasj.2013.21.6.227

Al-Zahrani, A. M. (2015). From passive to active: The impact of the flipped classroom through social learning platforms on higher education students' creative thinking. British Journal of Educational Technology, 46(6), 1133-1148. https://doi.org/10.1111/bjet.12353

Ashton, H., \& Zalzala, A. (2000). Enhancing traditional learning: The use of multimedia material on the Internet. In the 8th Annual Conference on Teaching of Computing, Edinburgh.

Bawaneh, S. S. (2011). The effects of blended learning approach on students' performance: Evidence from a computerized accounting course. Interdisciplinary Journal of Research in Business, 1(4), 43-50. Retrieved from http://www.idjrb.com/articlepdf/idjrbjournal51.pdf

Bergmann, J., \& Sams, A. (2012). How the flipped classroom is radically transforming learning. The Daily Riff, pp. 1-3.

Bonk, C. J., \& Graham, C. R. (2006). Handbook of blended learning: Global Perspectives. San Francisco, CA: 
Pfeiffer Publishing.

Cakir, I. (2015). Opinions and Attitudes of Prospective Teachers for the Use of Mobile Phones in Foreign Language Learning. Online Submission, 6(3), 239-255.

Danker, B. (2015). Using Flipped Classroom Approach to Explore Deep Learning in Large Classrooms. The IAFOR Journal of Education, 3(1), 171-186. https://doi.org/10.22492/ije.3.1.10

Farah, M. (2014). The Impact of Using Flipped Classroom Instruction on the Writing Performance of Twelfth Grade Female Emirati Students in the Applied Technology High School (ATHS) (Master's thesis, The British University in Dubai).

Jassem, J. A. (2000). Study on second language learners of Arabic: An error analysis approach. Kuala Lumpur: Noordeen.

Ke, F., \& Kwak, D. (2013). Constructs of Student-Centered Online Learning on Learning Satisfaction of a Diverse Online Student Body: A Structural Equation Modeling Approach. Journal of Educational Computing Research, 48(1), 97-122. https://doi.org/10.2190/EC.48.1.e

Lazareva, V. (2015). Perception of Flipped Classrooms by the Teachers of TAMK (Bachelor's thesis, Tamprere University of Applied Siences, Finland).

Li, L., \& Guo, R. (2015). A student-centered guest lecturing: A constructivism approach to promote student engagement. Journal of Instructional Pedagogies, 15, 1-7. Retrieved from http://www.aabri.com/copyright.html

Obeidat, R. A., \& Abu-Shanab, E. A. (2010). Drivers of e-government and e-business in Jordan. Journal of Emerging Technologies in Web Intelligence, 2(3), 204-211. https://doi.org/10.4304/jetwi.2.3.204-211

Oliver, M., \& Trigwell, K. (2005). Can blended learning be redeemed? E-Learning and Digital Media, 2(1), 17-26. https://doi.org/https://doi.org/10.2304/elea.2005.2.1.2

Rababah, L., Melhem, N. B., Jdaitawi, M., Rababah, B., \& Rababah, O. (2012). EFL teachers' barriers to the use of ICT in instruction in Jordan. In First International Conference on Behavioural and Social Science Research (November 2), Kampar, Malaysia.

Rababah, L., \& Melhem, N. B. (2015). Investigation into Strategies of Creativity in EFL Writing in Jordan. Journal of Literature, Languages and Linguistics, 3(5), 14-25.

Seraj, S. A. (2010). Attitudes of Teachers of Arabic as a Foreign Language toward Methods of Foreign Language Teaching.

Strayer, J. F. (2012). How learning in an inverted classroom influences cooperation, innovation and task orientation. Learning Environments Research, 15(2), 171-193. https://doi.org/10.1007/s10984-012-9108-4

Tai, Y., \& Ting, Y.-L. (2011). Adoption of mobile technology for language learning: Teacher attitudes and challenges. The JALT CALL Journal, 7(1), 3-18.

Uzunboylu, H., \& Ozdamli, F. (2011). Teacher perception for m-learning: scale development and teachers' perceptions. Journal of Computer Assisted Learning, 27(6), 544-556. https://doi.org/https://doi.org/10.1111/j.1365-2729.2011.00415.x

\section{Copyrights}

Copyright for this article is retained by the author(s), with first publication rights granted to the journal.

This is an open-access article distributed under the terms and conditions of the Creative Commons Attribution license (http://creativecommons.org/licenses/by/4.0/). 